\title{
Successful Techniques to Recruit Hispanic and Latino Research Participants
}

\author{
Mandy Sha', Georgina McAvinchey', Rosanna Quiroz', Jennifer Moncada' \\ ${ }^{1}$ RTI International \\ Keywords: hard-to-reach, spanish, limited english speakers, research participation, latinos, hispanic, respondent recruitment \\ https://doi.org/10.29115/SP-2017-0014
}

\begin{abstract}
This paper is the third in a series of Survey Practice articles focused on recruiting hard-to-reach limited English speakers as research participants. Previous articles conducted systematic analyses of recruitment records and found that recruiting through word of mouth worked best to recruit Asians who speak little or no English. Anecdotally, our experience over the past decade supports similar observations for the recruitment of Hispanics and Latinos with limited English proficiency. To provide comprehensive and pragmatic recommendations (including what to say and what not to say in Spanish), we synthesized recruiter debriefing findings from two recruitment efforts for qualitative research. In both efforts, the recruiters enrolled Hispanic/Latino research participants who spoke little or no English and met a set of hard-to-reach characteristics that informed the goals of the research. We identified successful strategies as follows: recruiting in-person to maximize the benefit of the word-of-mouth method, building rapport and trust in the recruitment introduction, calming fear and the perception of risk, and personalizing the benefits of participation. We also established a profile of the successful recruiter that can be used as a guide by researchers who wish to identify and train recruiters.
\end{abstract}

\section{Introduction}

Recruitment consists of identifying, screening, and enrolling participants in the research studies. As Felsen et al. (2010) states, recruiters may be more effective if they adapt to participants' needs and successfully build rapport with them, and the likelihood of recruitment success may be increased by anticipating potential recruitment barriers and providing training. While strategies for recruiting racial and ethnic minority participants have been well documented (e.g., Horowitz et al. 2009; Maxwell et al. 2005; Reed et al. 2003; Roosa et al. 2008), the recruitment of limited English speakers has not been studied as extensively. Recent literature suggests that Asians who speak little or no English are hard to recruit because of a general lack of experience participating in surveys or social science research (Park and Sha 2014). As a result, there was distrust toward the recruiter and the study. Recruiting them through word of mouth and by recruiters with strong ties to the ethnic community work best, according to systematic analyses of recruitment records by Liu, Sha, and Park (2013), Park and Sha (2014), and Park and Sha (2015). 
Hispanics and Latinos who speak limited or no English are also hard to recruit. ${ }^{1}$ Anecdotally, our decade-long experience recruiting among this population for qualitative, cognitive interview studies to evaluate Spanish language instruments suggested that they tended to be less acculturated or might not have participated in research studies of any kind. Some distrusted government sponsors, citing news reports or concerns about deportations of undocumented immigrants. Others appeared to simply wish to remain anonymous and to not bring attention to themselves. The recruitment challenges were even greater when the study required participants with specific characteristics to test Spanish survey items designed for respondents with those characteristics, for example, living situations such as housing subsidy recipients or recent immigrants from specific origins (e.g., afroamericanos [Afro Hispanic], indigenous).

What are successful strategies to recruit Hispanic/Latino limited English speakers as research participants? To answer this question, we adapted the peer debriefing method used by qualitative researchers and applied it to two recruitment efforts. The findings from the debriefings were synthesized to form the basis of our recommendations for successful recruitment strategies.

\section{Method}

Peer debriefing involves the use of impartial and knowledgeable peers to provide feedback on the data to enhance the credibility of a qualitative study (Lincoln and Guba 1985). Roller and Lavrakas (2015) advocated the use of peer debriefing during the data gathering and data analysis stage to verify the researcher's findings and interpretations. Traulsen, Almarsdóttir, and Björnsdóttir (2004) structured peer debriefing into interviewing the moderator. This technique collects moderator reflections on factors that contribute to the focus group discussion outcome.

We adapted the peer debriefing method and collected debriefing comments among recruiters from the same organization. There were three types of peer debriefings about the recruitment of Hispanic/Latino limited English speakers: (1) verbal recruiter debriefings during the data collection period with open-ended discussions, (2) verbal and/or written recruiter debriefing at the end of the study with structured discussions, and (3) volunteered selfdebriefing notes about the participants from the text interview summaries. We compared and synthesized the debriefing findings from this team of recruiters' effort from 2008 (Sha et al. 2010) and their recent, similar effort from late 2014 to early 2015.

\footnotetext{
1 While there is a degree of universality in the Spanish language, there are differences in word use among speakers from various Hispanic/Latino
} origins. To represent the diverse Spanish uses, it is necessary to recruit a variety of Hispanic/Latino origins. 
Table 1 Summary of the two preinterview recruitment efforts.

Differences

1. Each effort had two recruiters from RTI International, and two recruiters worked on both efforts

2. The 2008 recruitment lasted from June to October and selected 48 participants vs. the more recent recruitment that took place from November 2014 to February 2015 and selected 48 participants

3. The 2008 effort focused on recruiting participants in various housing structures and ownership types. The 2014-2015 effort's recruited complex household compositions (e.g., non-nuclear families, same-sex partner, etc.) and Hispanic/Latino origins (indigenous, afroamericanos), and over half of the recruits were required to be proficient mobile device users
Similarities

1. All recruiters were experienced, fully bilingual, and bicultural

2. Trainings minimized recruiter inconsistencies, and they also conducted interviews.

3. Used nonscripted recruitment introduction by consulting talking points or sample script

4. Recruitment methods: word of mouth, newspaper and online ads, and flyers at locations frequented by potential recruits

5. Government sponsor: U.S. Census Bureau

6. Objectives were to pretest Spanish survey questions primarily about housing and demographics $^{a}$

7. Length of interview: on average 60 minutes

8. Incentive payment: $\$ 40$

9. Locations: North Carolina and Texas, except Floridab

\footnotetext{
${ }^{a}$ The 2008 work pretested selected questions of the American Housing Survey and the 2014-2015 work pretested versions of Census questionnaires that may be used in the 2020 Census. We believe this is an acceptable variation because we are interested in the pre-interview recruitment efforts only and that these surveys shared housing and demographic topics.

${ }^{b}$ The 2014-2015 effort also included Florida because some areas there have a higher concentration of afroamericanos (Afro-Hispanics) needed to inform the research objective.
}

Table 1 summarizes the differences and similarities between the two recruitment efforts. We believe it is appropriate to consider these two efforts in our analysis of peer debriefings because our goal is to inform successful recruitment strategies. We also want to highlight the consistently successful strategies over time. We define success by that the recruiters enrolled hard-toreach Hispanic/Latino research participants who spoke little or no English and met the set of characteristics that informed the goals of the research.

\section{Findings and Recommendations}

We identified three successful strategies to recruit hard-to-reach Hispanic/ Latino research participants: (1) recruit in-person to maximize the benefit of the word-of-mouth method, (2) practice techniques that encourage recruits' cooperation, and (3) consider the profile of the successful recruiter. 


\section{In-Person and Word-of-Mouth Recruitment}

The recruiters felt that recruiting in person in the community worked best with hard-to-reach Hispanics/Latinos because the face-to-face interactions helped establish trust. For example, the North Carolina recruiters approached potential research participants at large social events, such as at a "festival", e.g., a music festival. They familiarized themselves with the places frequented by potential recruits, such as Hispanic restaurants; grocery stores; community centers; churches with Spanish services; English learning centers; Hispanic affairs offices; and places with signs such as "washerías" (laundromats), "peluquerías" (hair salons), etc.

In the 2015 effort, the Florida recruiter identified afroamericanos (Afro Hispanics) and indigenous participants by interacting directly with potential recruits in areas that they frequented. The recruiter noted that when she presented herself well and related to the potential participants, it was harder for them to say "no" in person. She had also first studied the area before making an in-person visit. For example, she identified a language school that taught English to Hispanics/Latinos from various Latin American countries. She used a private area inside the school for screening and interviewing, obtained permission from trusted figures (i.e., the teachers) before approaching the students, and encourage word of mouth to attract more potential recruits to be screened. In North Carolina, the recruiters also asked trusted figures recognized Hispanic/Latino leaders - to spread the word. For example, a priest made an announcement after a Spanish language mass that the recruiter was in the area.

In-person recruitment usually generates useful leads. For example, the Florida recruiter went to a supermarket in an area where a cluster of indigenous Central Americans often visited. She first recruited two people at the supermarket and asked them to help her meet more people from their community, and they suggested that the recruiter go to a small store and a church. The recruiter eventually identified more people who self-identified as indigenous. The Texas recruiter also identified potential recruits after visiting a Hispanic community center.

We always paired in-person recruitment with ads about the study, such as newspaper ads, online ads, and flyers. The recruiters noted that the callers who answered an ad were more motivated to participate, tended to be more acculturated, or spoke English well. But they might not have the type of characteristics that the study was looking for, and we would not know until the end of the screening. Based on these observations, when recruiting specific characteristics among Hispanics/Latinos, we recommend using advertisements as the secondary recruitment method. We recommend in-person recruiting as the primary method. 
Table 2 Attire, verbal behavior, and nonverbal behavior of a recruiter.

\begin{tabular}{|c|c|c|}
\hline \multirow[t]{2}{*}{ Attire } & $\bullet$ & $\begin{array}{l}\text { Dress business casual, for example, pants or a modest skirt in solid, neutral colors (black, navy, grey); a shirt; a } \\
\text { sweater; or a simple jacket. }\end{array}$ \\
\hline & $\bullet$ & $\begin{array}{l}\text { Avoid too many accessories, tight or revealing clothes, suits, clothing or purses with designer logos, and high } \\
\text { heels. Also avoid a casual look with jeans, shorts, T-shirts or bulky coats unless it is part of a uniform. }\end{array}$ \\
\hline \multirow{2}{*}{$\begin{array}{l}\text { Verbal } \\
\text { behavior }\end{array}$} & $\bullet$ & Greet politely in Spanish, e.g., Buenos días/Buenas tardes(Good morning/ Good afternoon) \\
\hline & • & $\begin{array}{l}\text { Use the formal form of address, usted, to talk to potential adult participants. Younger adults (less than } 30 \\
\text { years old) might feel more comfortable if they are addressed in an informal form, but when in doubt, use the } \\
\text { formal form. Addressing adults in an informal form,tú, could be perceived as disrespectful, especially if the } \\
\text { recruiter is younger than the potential recruits. }\end{array}$ \\
\hline \multirow[t]{2}{*}{$\begin{array}{l}\text { Nonverbal } \\
\text { behavior }\end{array}$} & • & $\begin{array}{l}\text { Make eye contact, but do not fix your gaze. Gazing could make potential recruits uncomfortable and } \\
\text { distrustful. }\end{array}$ \\
\hline & $\bullet$ & $\begin{array}{l}\text { Display a friendly, but modest smile. Overdoing it might be perceived as trying to sell something or even } \\
\text { flirting. }\end{array}$ \\
\hline
\end{tabular}

\section{Gaining Cooperation Techniques}

When recruiting in person, the debriefing findings suggested that the recruiters must gain trust by building rapport, calming fear and perception of risk, and personalizing the benefits of participation. To do this, the recruiters tailored their approach by watching the potential recruits' body language and reactions and re-emphasized key points. We believe some of these techniques are also applicable when interacting with potential recruits over the telephone or social media.

\section{BUILDING RAPPORT}

Below are the elements that the recruiters felt were crucial when talking to a potential recruit:

- Show identification badge to legitimize your presence.

- Mention your own national origin, or having visited a Spanishspeaking country in Latin America, as a way of relating to the participants.

- Emphasize that you are not selling anything and that you need their help.

- Indicate ties to participants' immediate community, such as membership to or support for the same local organizations.

- Be flexible - if potential recruits indicate that they are too busy, offer to screen them later or the next day, and always get their contact information.

- Hand out flyers, so potential recruits walk away with something that has your contact information.

Table 2 summarizes the attire and verbal and nonverbal behaviors that the recruiters suggested to have incorporated as part of the recruitment introduction. 


\section{CALMING FEAR AND PERCEPTION OF RISK}

- Emphasize again that we are not selling anything or asking for money.

- De-emphasize that this is an 'entrevista' (interview) because this word could give the impression of an immigration entrevista, especially when the study has a government sponsor. Describe the essence of the cognitive interview that it is 'una conversación' (a conversation), like this: 'Es solamente una conversación, donde usted me dice lo que piensa' (it's just a conversation; you tell me what you think).

- Explain that there are no right or wrong answers and that we just want your opinion to improve the questionnaire, so that the Spanish language questions are clearly understood by most Spanish-speakers from different countries.

- The word 'confidencialidad' (confidentiality) can be a big word. Simplify the concept by saying that it means not sharing information with anyone outside of the project team (if applicable). If needed, mention the legal consequences to the recruiters for divulging their information, i.e., potential loss of job, jail time, and fines.

- Do not describe the survey using its proper term in Spanish, 'investigación', because it also means “investigation” in Spanish. We recommend saying estudio (study).

- (To address fear related to immigration) Assure that their information will not be shared or used for anything related to immigration, and reiterate the objectives of the research study and how their information is protected.

\section{PERSONALIZING BENEFITS AND CONVENIENCE}

- Describe the potential benefits to the immediate, local community, not just the Hispanic/Latino community in general.

- Stress that the interview can be scheduled at a time and location most convenient to the participant, for example, close to home or close to work.

- Point out that the incentive money could be used for grocery shopping or for gas.

- Describe that they could help make the Spanish translation easier to understand for all Spanish speakers. (As limited English speakers, they most likely have read poor Spanish translations before.) 
Table 3 Successful recruiter profile.

\begin{tabular}{lll}
\hline Dimension & Performance measures \\
Characteristics & $\sqrt{ }$ & Fully bilingual in Spanish and English (formal education or training) \\
& $\sqrt{ }$ & Strong ties to the Hispanic/Latino community \\
& $\sqrt{ }$ & Comfortable with approaching strangers and key community figures \\
Experience & $\sqrt{ }$ & Experienced with recruiting Hispanic/Latino non-English speakers \\
& $\sqrt{ }$ & Familiar with the recruitment area \\
Training & $\sqrt{ }$ & Fully comprehend dynamic quota criteria for recruitment \\
& $\sqrt{ }$ & Properly trained on the study specifics \\
& $\sqrt{ }$ & Ideally cross-trained to conduct interviews \\
& $\sqrt{ }$ & Tailor the recruitment introduction to the potential recruits \\
$\sqrt{ }$ & Avert or convert refusals without causing harassment \\
& $\sqrt{ }$ & Flexible to participants' preference for interview scheduling and locations \\
& $\sqrt{ }$ & Be a team player to collaborate with and mentor fellow recruiters
\end{tabular}

\section{Profile of the Successful Recruiter}

Based on the debriefing findings, we established a profile of the successful recruiter. A recruiter who demonstrates the characteristics, experience, training, and behaviors shown in Table 3 is likely to be successful when recruiting hard-to-reach Hispanic/Latino research participants. We encourage researchers to use this profile as a guide to identify recruiters for future studies and also incorporate them into recruiter trainings.

\section{Caveats About In-Person and Word-of-Mouth Recruitment and Noticeable Changes over Time}

As our debriefing syntheses suggested, an introduction from a public figure, such as a priest, an English teacher, or a community leader, is crucial. It helps establish the recruiter's legitimacy and trustworthiness. However, establishing rapport with the public figure and gaining their trust is also challenging. In our experience, some priests or community leaders act as gatekeepers and do not allow any anuncios (advertisement, announcement) in their congregation or organization. Our recruitment efforts were sometimes deterred by gatekeepers in large churches and organizations in urban areas. Smaller parishes or groups in less populated towns appeared to be more open to introducing recruiters to potential recruits. Because it can be time-consuming to recruit in person, and through word of mouth, we recommend this method only for when recruiting hard-to-reach, specific characteristics.

In addition, we noticed some changes between the 2008 and the 2014-2015 recruitment efforts. As an incentive to participate, we paid participants $\$ 40$, which was the amount mandated by the Office of Management and Budget. There were a few instances in the 2015 effort where $\$ 40$ was not attractive enough to encourage participation. Another change we have noticed is that it 
is much easier these days to become familiarized with a recruitment area by doing thorough Internet searches. The recruiters can be more prepared than ever before approaching potential recruits.

Furthermore, in the 2014-2015 effort, we encountered more second or even third generation Hispanics/Latinos than we did in 2008. As descendants of immigrants from Spanish-speaking countries, they may consider themselves to be Hispanic/Latino, but Spanish may no longer be their dominant language, or they do not speak Spanish at all. To ensure that the potential recruits are native Spanish speakers, the recruiters sometimes had to ask them directly in Spanish if they spoke Spanish. Another observation related to the Spanish language we made is that nowadays there are many non-Hispanics who speak fluent Spanish and could be trained as recruiters. We suspect though that potentialHispanic/ Latino participants would be more receptive when approached by recruiters who share their background. In addition, all our recruiters were women. The influence of the recruiter's ethnicity and sex is an area for future research.

\section{Disclaimer}

This paper is released to inform interested parties of research and to encourage discussion of work in progress. Any views expressed on (statistical, methodological, technical, or operational) issues are those of the authors and not necessarily those of the U.S. Census Bureau.

\section{Acknowledgement}

The authors thank U.S. Census Bureau researchers for conducting Spanish language research studies. We also acknowledge Dr. Murrey Olmsted for providing comments on an earlier version of this paper. 


\section{REFERENCES}

Felsen, C.B., E.K. Shaw, J.M. Ferrante, L.J. Lacroix, and B.F. Crabtree. 2010. "Strategies for In-Person Recruitment: Lessons Learned from a New Jersey Family Medicine Research Network (NJFMRN) Study." Journal of the American Board of Family Medicine 23 (4): 523-33.

Horowitz, C., B. Brenner, S. Lachapelle, D. Amara, and G. Arniella. 2009. "Effective Recruitment of Minority Populations through Community-Led Strategies." American Journal of Preventive Medicine 376 (6 Suppl 1): S195-200.

Lincoln, Y.S., and E.G. Guba. 1985. Naturalistic Inquiry. Beverly Hills, CA: Sage.

Liu, L., M. Sha, and H. Park. 2013. "Exploring the Efficiency and Utility of Methods to Recruit NonEnglish Speaking Qualitative Research Participants.” Survey Practice 6 (3): 1-8.

Maxwell, A.E., R. Bastani, P. Vida, and S. Warda. 2005. "Strategies to Recruit and Retain Older Filipino-American Immigrants for a Cancer Screening Study.” Journal of Community Health 303: $167-79$.

Park, H., and M. Sha. 2014. "Evaluating the Efficiency of Methods to Recruit Asian Research Participants." Journal of Official Statistics 30 (2): 335-54. https://doi.org/10.2478/jos-2014-0020.

- - . 2015. “Do Different Recruitment Methods Reach Different Asian Demographics?” Survey Practice 8 (4): $1-8$.

Reed, P.S., K.L. Foley, J. Hatch, and E.J. Mutran. 2003. "Recruitment of Older African Americans for Survey Research: A Process Evaluation of Community and Church-Based Strategy in the Durham Elders Project." The Gerontologist 43 (1): 52-61.

Roller, M.R., and P.J. Lavrakas. 2015. Applied Qualitative Research Design: A Total Quality Framework Approach. Guilford, New York.

Roosa, M., F. Liu, M. Torres, and N. Gonzales. 2008. "Sampling and Recruitment in Studies of Cultural Influences on Adjustment: A Case Study with Mexican Americans.” Journal of Family Psychology 22 (2): 293-302.

Sha, M., G. McAvinchey, S. Rodriguez, and G. Carter. 2010. "Respondent Recruitment, Interviewing and Training: Lessons Learned from a Spanish Language Cognitive Interviewing Project." In JSM Proceedings, 65th Annual Conference of the American Association for Public Opinion Research, 6372-81. Alexandra, VA: American Statistical Association.

Traulsen, J.M., A.B. Almarsdóttir, and I. Björnsdóttir. 2004. "Interviewing the Moderator: An Ancillary Method to Focus Groups.” Qualitative Health Research 14 (5): 714-25. 